\title{
Expanding the Population Health Workforce: Strategic Priorities of Hospital Organizations in the United States
}

\author{
Cory E. Cronin, $\mathrm{PhD},{ }^{1}$ Berkeley Franz, $\mathrm{PhD}{ }^{2}$ and Kristin A. Schuller, $\mathrm{PhD}^{1}$
}

\begin{abstract}
The role of hospital contributions to population health is a topic increasingly worthy of attention in the years since the Affordable Care Act. To explore how hospitals themselves consider their role as population health leaders, the authors analyzed data from the 2015 American Hospital Association Annual Population Health Survey, which asks organizations about which strategic priorities should be expanded in order to strengthen their organization's population health workforce. Descriptive statistics for the study sample of 1418 hospitals show that physicians were the most commonly ranked priority, followed by behavioral health professionals. Using multivariate analysis, the professional roles identified were grouped into 5 categories: behavioral health, clinical, data collection, business functions, and social supports and services. Doing so revealed that different types of hospitals were more likely to identify different types of roles as more important. Larger hospitals were more likely than others to identify behavioral health and clinical roles. For-profit hospitals were less likely to prioritize data collection and social determinants than their nonprofit peers. These findings provide important insight for public health professionals regarding the staffing priorities of hospitals within their communities. Many population health programs may not be moving beyond traditional clinical expertise to engage the upstream determinants of health in their communities.
\end{abstract}

Keywords: hospitals, population health, social determinants

\section{Introduction}

$\mathbf{T}$ He American health care system is currently undergoing broad transformation in response to a variety of forces - rising health care costs, changing community benefit regulations, and persistent health disparities. Although health care organizations remain focused on providing evidencebased clinical care, many organizations are expanding their focus beyond patients to address population-level health outcomes in line with the Triple Aim. ${ }^{~}$ In doing so, health care organizations are beginning to develop new preventive efforts and engage the social determinants of health, or the social environments that predispose individuals to both health and illness in the United States. ${ }^{2}$ The term "population health," coined by Kindig and Stoddart, ${ }^{3}$ best represents this renewed focus on the health outcomes not only of patients, but of entire populations that hospitals and health care organizations serve. Although there is important evidence that health care organizations are adopting population health initiatives, ${ }^{4}$ very little is known about how organizations are being reshaped by this new framework and how hospitals specifically are adapting their workforce to meet the needs of local communities.

In recent years, several mechanisms have encouraged health care organizations to cultivate initiatives to address population health and to develop partnerships with a broad range of community-based organizations as well as health departments. Important changes have led to the increasing focus on population health, including changing reimbursement structures, ${ }^{5,6}$ the expansion of community benefit requirements for nonprofit hospitals in the Affordable Care Act (ACA), ${ }^{7,8}$ and growing evidence on population-based health care. The result is a new model of health care that relies heavily on community-based partnerships, prevention, and engagement with upstream social determinants of health in an effort to improve outcomes and reduce costs. ${ }^{9,10}$

\footnotetext{
${ }^{1}$ College of Health Sciences and Professions, Ohio University, Athens, Ohio, USA.

${ }^{2}$ Heritage College of Osteopathic Medicine, Ohio University, Athens, Ohio, USA.
} 


\section{Building a population health infrastructure}

Although important progress has been made in transitioning toward increased population health engagement, the process that health care institutions, and hospitals in particular, have been undergoing has been relatively understudied. From this still developing literature, it is known that hospitals have faced barriers to adopting population health models, including building a rationale for increased expenditures on social supports and services that address nonmedical factors, developing metrics to demonstrate financial and population health impact, and cultivating trust among community members. ${ }^{11,12}$ Still, there is evidence that hospitals are successfully engaging community-based partners to carry out population health work and that the ACA's new requirements have encouraged collaboration between hospitals, local communitybased organizations, and local health departments. ${ }^{13,14}$

For example, a recent study found that the majority of public health departments are partnering with local hospitals to carry out Community Health Needs Assessments (CHNAs) and plan population health programming. ${ }^{15}$ A number of studies also have documented partnerships between universities and hospitals, in which academic centers were able to help facilitate data collection, collaborate with planning interventions to address identified needs, and train health professions students in community-based participatory research. ${ }^{16,17}$ Hospitals also have partnered with a host of government and community-based organizations, including city planners, advocacy groups, local schools, social service agencies, providers of legal aid, and environmental groups. ${ }^{12,18,19}$ Although the degree of collaboration and community input varies, ${ }^{20}$ these studies suggest that partnerships may be essential to overcoming some of the barriers identified in adopting population health models within hospital organizations.

There also has been definitional disagreement surrounding what role hospitals should play in population health. ${ }^{21}$ The most commonly cited definition, by Kindig, defines population health as: "the health outcomes of a group of individuals, including the distribution of such outcomes within the group." 3 This definition is expansive and suggests that hospital initiatives should engage all individuals within a community and seek to eliminate disparities across populations. ${ }^{22}$ Others have focused on a more specific role for health care organizations, often called "population health management," that emphasizes existing patient populations to ensure that all clinical and social needs are met. The broad goals of population health management are to improve health outcomes and quality of care, and to reduce costs. ${ }^{23}$ Examples of population health management within hospitals include: the creation of behavioral health care management bridging strategies ${ }^{24}$ and partnerships with community health departments ${ }^{14}$ and community pharma$\operatorname{cies}^{25}$; the extension of pharmacist' roles through creation of Medication Therapy Disease Management Programs ${ }^{26}$; stewardship of controlled substances in communities ${ }^{27}$; leveraging electronic medical record systems for improved disease management and continuity of care ${ }^{28,29}$; and development of an alert system that notifies primary care providers when a patient visits the emergency department. ${ }^{30}$

Recent research gives hospitals further reasons to consider expanding their traditional responsibilities and to be more attentive to social determinants of health. In their assessment of longevity estimation models, Kaplan and Milstein ${ }^{31}$ conclude that access to medical care accounts for only about $10 \%$ of premature deaths, while behavioral and social factors are a greater influence. Furthermore, when assessing the importance of social needs programs, $84 \%$ of health professionals supported the addition of social needs assessments as a routine part of clinical care processes, with the goal of improved trust, communication, and care delivery. ${ }^{32}$ Such findings may contribute to hospitals' development of strategies and partnerships to focus more on health needs beyond their clinical offerings. The extent to which hospitals are pursuing opportunities to do this varies, as do the means they employ, with some hospitals collaborating closely with community partners beyond the medical sector while others prefer to focus on more traditional relationships or to remain independent. ${ }^{33}$

Little is known about how hospitals envision population health responsibilities and how they are adapting their organizations to address the needs of both patients and their broader communities. Addressing upstream social determinants of health and the social needs of patients is an important change for many hospitals, and there is a need to better understand how staffing is changing in response to population health growth and where hospitals are making personnel and organizational changes.

This study examines what hospitals anticipate their staffing priorities to be in addressing future population health issues, as reported by the hospitals themselves. In analyzing the professional roles hospitals consider to be the most important to population health, this study is identifying where hospitals are likely to put their resources and what factors of population health they see themselves as most readily willing and able to respond to. By studying the relationship between both hospital and community characteristics and population health strategic priorities, trends or patterns can be recognized, which may better enable public health officials and policy makers to know how to engage with hospitals in collaborative population health efforts.

\section{Methods}

This study analyzed data from the 2015 American Hospital Association (AHA) Population Health Survey, with a sample of 1418 responding hospitals from across the United States. Each year AHA surveys hospitals across the United States to gain information about the characteristics and functions of the hospital population. The population health survey contains additional questions on hospital engagement with population health and the way in which they structure their strategies. ${ }^{34}$ The 1418 respondents to the Population Health Survey represent approximately $30 \%$ of the hospitals that responded to the general AHA Annual Survey, and approximately $23 \%$ of the 6251 hospitals associated with AHA. Within this survey supplement, the main question of interest for this study is: "Over the next three years, what kinds of professional backgrounds and experiences will be most important for your organization's staff involved in future population health activities? Please rank only the top five with one being the most important." Hospitals were able to select from a list of 17 listed options or write in their own. 
Hospital responses to this question make up the dependent variable. For the analysis, the options were grouped into 5 categories: clinical roles (including nurse, physician, and clinical non-nurse/physician); data driven (including epidemiology and biostatistics, needs assessment and strategic planning, and program evaluation); social supports and services (including community health and organization, health education, human or social services, public health/ socioeconomic development, and public policy); business functions (including change management, communications, finance, health administration, and nonprofit management), and behavioral health.

The independent variables include hospital characteristics collected by the AHA 2015 Annual Survey. These characteristics were matched to each hospital participating in the AHA Population Health Survey. AHA data were further supplemented with county and community characteristic data sourced from the Area Health Resource File and County Health Rankings. ${ }^{35,36}$ Independent variables include: number of beds in the hospital $(<50 ; 50-199 ; 200-399 ; \geq 400)$; ownership status (nonprofit, public, investor); system membership (no, yes); teaching hospital status (no, yes); general medical center (no, yes); psychiatric hospital (no, yes); longterm care hospital (no, yes); children's hospital (no, yes); specialty hospital (no, yes); other service hospital (no, yes); urban (no, yes); uninsured rate (continuous); poverty rate (continuous); the percentage of adults reporting fair or poor health (continuous); and region (Northeast, Midwest, West, South) (Table 1).

Table 1. Descriptive Statistics of Key VARIABLES $(N=1401)$

\begin{tabular}{lcc}
\hline & $\begin{array}{c}\text { Frequency/ } \\
\text { mean }\end{array}$ & $\begin{array}{c}\text { Percent/ } \\
\text { Std err }\end{array}$ \\
\hline Bed size & Mean 184.08 & Std Err 5.63 \\
Bed size: $>50$ & 434 & $30.98 \%$ \\
Bed size: 50-199 & 509 & $36.33 \%$ \\
Bed size 200-399 & 281 & $20.06 \%$ \\
Bed size: $\geq 400$ & 177 & $12.63 \%$ \\
Ownership: nonprofit & 862 & $61.53 \%$ \\
Ownership: public & 381 & $27.19 \%$ \\
Ownership: investor & 158 & $11.28 \%$ \\
System member & 799 & $57.03 \%$ \\
Teaching & 123 & $8.78 \%$ \\
General medical center & 1170 & $83.51 \%$ \\
Psychiatric hospital & 99 & $7.07 \%$ \\
Long-term care hospital & 34 & $2.43 \%$ \\
Children's hospital & 25 & $1.78 \%$ \\
Specialty hospital & 46 & $3.28 \%$ \\
Other service hospital & 27 & $1.93 \%$ \\
Urban & 896 & $63.95 \%$ \\
Uninsured rate & Mean 12.61 & Std Err .14 \\
Poverty rate & Mean 15.87 & Std Err .15 \\
Population health; poor/fair & Mean 16.05 & Std Err .001 \\
Region: Northeast & 217 & $15.49 \%$ \\
Region: Midwest & 478 & $34.12 \%$ \\
Region: West & 250 & $17.84 \%$ \\
Region: South & 456 & $32.55 \%$ \\
\hline
\end{tabular}

Source: American Hospital Association Population Health Survey $2015 .^{34}$

\section{Analytic strategy}

In addition to assessing descriptive statistics, this study employed ordered logistic regression to analyze the hospital and community characteristics associated with selecting each category, with consideration of hospital rankings. Each of the 5 categories served as a distinct dependent variable $(0=$ no, $1=$ yes $)$. Additionally, multinomial regression was used to evaluate the hospital and community characteristics associated with the category of the top ranked profession. For this analysis, the clinical category was used as the reference group. After accounting for missing data, the analytic sample consists of 1401 hospitals.

\section{Results}

Descriptive statistics identify that the most commonly selected role included in hospitals' rankings of importance to future public health efforts was physician, with $42 \%$ of hospitals including it as one of their 5 selections (Table 2). Following physician are behavioral health, community health organizing, nursing, and needs assessment/planning. Physician is also the most common role to be ranked first, followed by behavioral health. Looking at categories rather than specific roles, the clinical category is ranked first by $29 \%$ of hospitals, nearly twice as often as any other category. However, the social support and services category is the most represented among the entirety of the rankings, with $65 \%$ of hospitals listing at least one social support or service, followed by clinical and business functions (Figure 1).

The findings of the multivariate analysis indicate that each category of professional role has a significant relationship with several hospital or community characteristics (Table 3). The behavioral health category is significantly and positively related to larger hospitals, compared to those with $<50$ beds (odds ratios of 1.61, 1.66 and 2.09 for hospitals with 50-199 beds, 200-399 beds, and $\geq 400$ beds, respectively), system membership, public hospitals, and higher poverty rates. The clinical category is significantly and positively associated with larger hospitals, public hospitals, and system membership, and is negatively associated with teaching hospitals (Table 3 ). The data-driven category is significantly and positively associated with the largest hospitals and system membership, but negatively associated with higher uninsurance rates, public and for-profit ownership, and the Northeast region (as compared to the South) (Table 3). The social services and support category is significantly and positively associated with general medical hospitals and the county poverty rate, and negatively associated with for-profit ownership. The category of "other" is significantly and positively associated with system membership, the West region (as compared to the South), and being in an urban area, and negatively associated with forprofit ownership. Within the category of "other," the most commonly written in responses are associated with care coordination and case management. The business function category is not significantly related to any hospital or community characteristics (Table 3).

The multinomial regression analysis identifies hospital and community characteristics associated with the topranked category of professional role (Table 4 ). The clinical category serves as the reference group. The analytic sample for this analysis is 1129 hospitals because of missing data 


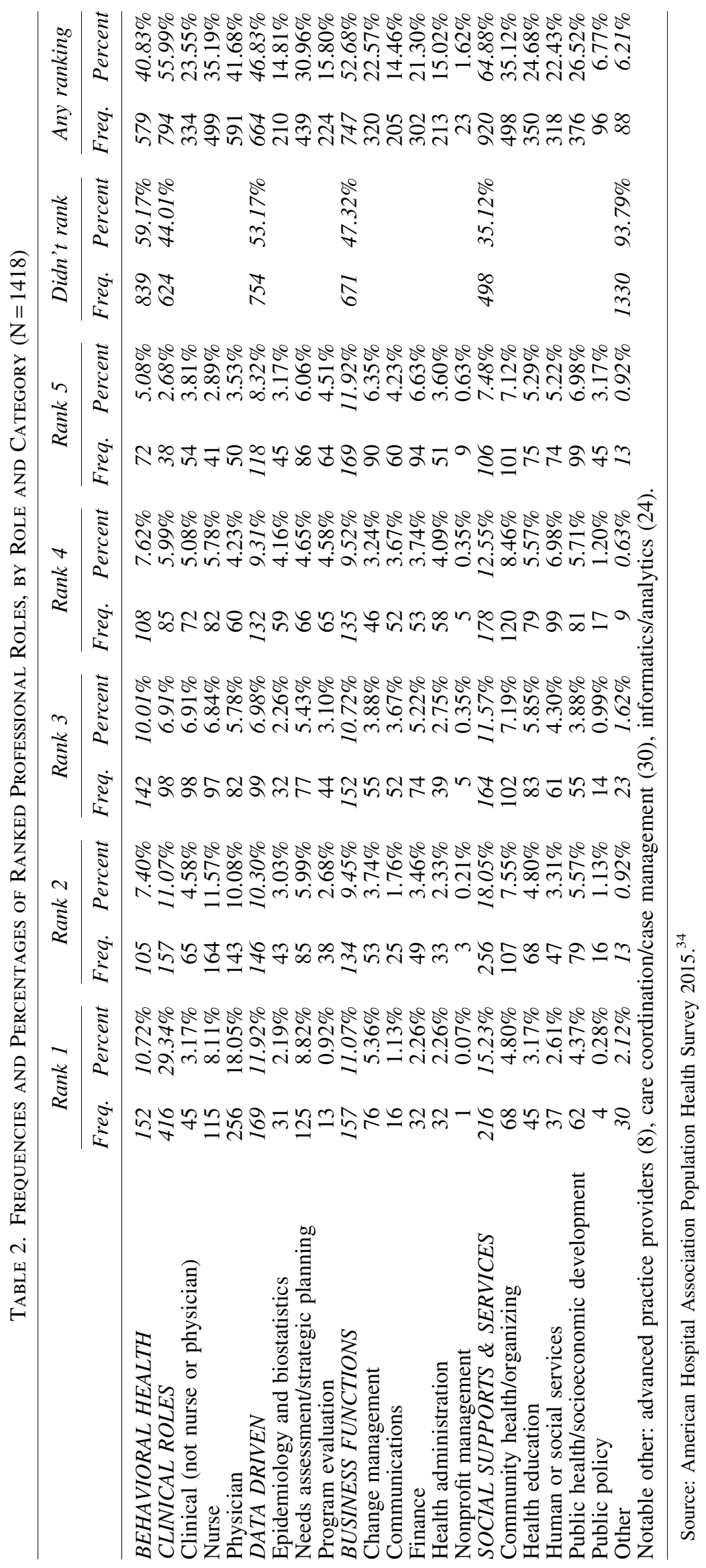




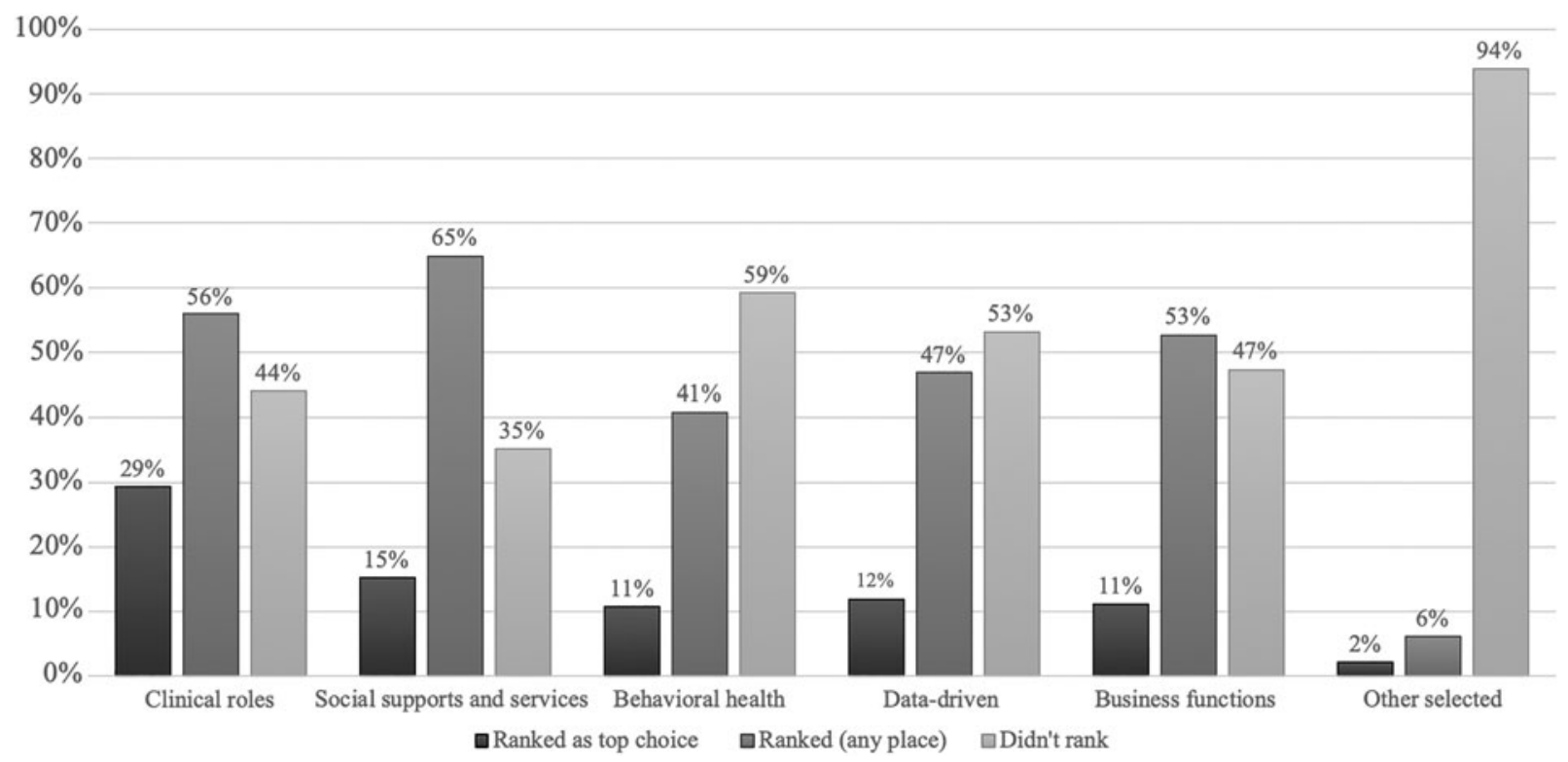

FIG. 1. Percentage of hospitals ranking each category of role.

for this measure. This analysis reveals that the social support and services category has a negative relationship to bed size (the relative risk ratios are 0.40 and .33 for hospitals with 200-399 beds and $\geq 400$ beds, respectively), with hospitals $>200$ beds significantly less likely to select a social support profession than a clinical profession. This also was true of for-profit hospital ownership. Poverty rate is significantly and positively related with a social support or service profession being ranked first, while fair or poor health rating is negatively associated (Table 4).

Prioritizing the data-driven category in the top ranking also is shown to have a significant and negative relationship with the fair or poor health rating, as compared to clinical. However, it is positively associated with teaching hospitals. The behavioral health category has a significant and negative relationship with general medical hospitals. For business functions, a significant and positive relationship is found with the uninsured rate. The category of "other" is significantly and positively associated with the West region, as compared to the South (Table 4).

\section{Discussion}

Hospitals are increasingly aware of the need to expand services and organizational practices to address populationlevel health in their patient populations and larger communities. A host of new consulting companies and screening tools have become available that support identification of key health needs and can inform new population health interventions. ${ }^{37}$ In addition, some health system payors have created incentives to address nonmedical needs that contribute to unnecessary health care utilization. ${ }^{38}$ To address population health needs, hospital organizations may need to expand their personnel in a variety of areas. Study findings show that as hospitals are weighing expansion of their population health efforts, they tend to value clinical expertise over other strategic priorities. Although this priority setting is certainly in line with the clinical services hospitals provide daily, it indicates that some hospitals may not be prioritizing a move beyond traditional clinical expertise to engage with upstream determinants of health in local communities or boosting their ability to assess local community health needs and evaluate population health efforts.

Despite the fact that clinical expertise is most commonly cited and ranked as number one, this study finds that many of the priorities hospitals cite have the potential to address nonmedical determinants of health. Looking at social supports and services more specifically, most hospitals recognize the value of their presence in partnerships to address nonclinical health issues, even though they are not as likely to describe social supports and services as a top priority. In fact, roles within the social supports and services category were included in $65 \%$ of hospitals' rankings, though only $15 \%$ list this expertise in the first spot. This means only $35 \%$ of hospitals did not list any social support roles, whereas $44 \%$ of the hospitals did not list a clinical role anywhere in their rankings. In other words, hospitals were likely to acknowledge the value of social service professionals in addressing important needs of patients and community members, but tended to consider clinical roles as the most essential strategic priority for future population health efforts. This finding suggests that hospitals may recognize the value of partnerships to address social determinants of health but may be hesitant about whether they should be leading this work from within their organizations. Policy makers and public health professionals should consider alternative mechanisms to encourage hospital participation in social services and increasingly raise awareness of the role that partnerships with public health professionals can play in improving population health.

In sharp contrast to support for social services, behavioral health had the smallest representation across the rankings (with the exception of "other"). This finding is important because there is recent evidence that behavioral health needs are common in patients utilizing hospital care and that these needs are often identified, though not necessarily addressed as part of the regular cycle of CHNAs for nonprofit hospitals. $^{39,40}$ Though behavioral health was listed as the first 
Table 3. Ordered Logistic Regression Hospital Ranking of Future Population Health Roles by Hospital AND COMmunity Characteristics ( $\mathrm{N}=1401$ Hospitals)

\begin{tabular}{|c|c|c|c|c|c|c|c|c|c|c|}
\hline \multirow[b]{3}{*}{ Bed size: $50-199$ (reference hospitals $<50$ beds) } & \multicolumn{5}{|c|}{ Clinical roles } & \multicolumn{5}{|c|}{ Social supports and services } \\
\hline & \multirow{2}{*}{$\begin{array}{c}\text { Odds } \\
\text { ratio }\end{array}$} & \multirow{2}{*}{$\begin{array}{c}\text { Std. } \\
\text { err. }\end{array}$} & \multirow{2}{*}{$\begin{array}{c}\mathrm{P}>z \\
0.046\end{array}$} & \multicolumn{2}{|c|}{$\begin{array}{c}{[95 \%} \\
\text { Conf. } \\
\text { interval] }\end{array}$} & \multirow{2}{*}{$\begin{array}{c}\begin{array}{c}\text { Odds } \\
\text { ratio }\end{array} \\
0.95\end{array}$} & \multirow{2}{*}{$\begin{array}{c}\text { Std. } \\
\text { err. }\end{array}$} & \multirow{2}{*}{$\begin{array}{c}\mathrm{P}>z \\
0.707\end{array}$} & \multicolumn{2}{|c|}{$\begin{array}{c}{[95 \%} \\
\text { Conf. } \\
\text { interval] }\end{array}$} \\
\hline & & & & 1.00 & 1.69 & & & & 0.74 & 1.22 \\
\hline Bed size $200-399$ (reference hospitals $<50$ beds) & 1.82 & $(0.30)$ & 0.000 & 1.32 & 2.52 & 0.87 & $(0.14)$ & 0.373 & 0.63 & 1.19 \\
\hline Bed size: $\geq 400$ (reference hospitals $<50$ beds) & 2.17 & $(0.48)$ & 0.000 & 1.41 & 3.33 & 0.91 & $(0.19)$ & 0.650 & 0.61 & 1.37 \\
\hline Ownership: Public (reference nonprofit) & 1.33 & $(0.17)$ & 0.021 & 1.04 & 1.70 & 0.82 & $(0.10)$ & 0.102 & 0.65 & 1.04 \\
\hline Ownership: Investor (reference nonprofit) & 0.96 & $(0.18)$ & 0.842 & 0.66 & 1.39 & 0.59 & $(0.11)$ & 0.003 & 0.41 & 0.84 \\
\hline System member & 1.54 & $(0.17)$ & 0.000 & 1.25 & 1.90 & 1.16 & $(0.12)$ & 0.138 & 0.95 & 1.42 \\
\hline Teaching & 0.55 & $(0.12)$ & 0.007 & 0.36 & 0.85 & 0.93 & $(0.19)$ & 0.719 & 0.62 & 1.39 \\
\hline General medical center & 1.30 & $(0.20)$ & 0.089 & 0.96 & 1.76 & 1.51 & $(0.23)$ & 0.006 & 1.12 & 2.02 \\
\hline Urban & 1.06 & $(0.14)$ & 0.648 & 0.82 & 1.37 & 0.84 & $(0.11)$ & 0.178 & 0.66 & 1.08 \\
\hline Uninsured rate & 0.98 & $(0.01)$ & 0.077 & 0.95 & 1.00 & 0.99 & $(0.01)$ & 0.485 & 0.96 & 1.02 \\
\hline Poverty rate & 1.00 & $(0.02)$ & 0.852 & 0.97 & 1.03 & 1.03 & $(0.02)$ & 0.049 & 1.00 & 1.06 \\
\hline Population poor, fair health & 1.02 & $(0.03)$ & 0.440 & 0.97 & 1.07 & 0.97 & $(0.02)$ & 0.149 & 0.92 & 1.01 \\
\hline Region: Northeast (reference South) & 0.90 & $(0.16)$ & 0.556 & 0.63 & 1.27 & 0.85 & $(0.15)$ & 0.357 & 0.61 & 1.19 \\
\hline Region: Midwest (reference South) & 0.88 & $(0.13)$ & 0.407 & 0.66 & 1.19 & 0.80 & $(0.11)$ & 0.111 & 0.60 & 1.05 \\
\hline \multirow[t]{3}{*}{ Region: West (reference South) } & 0.75 & $(0.12)$ & 0.071 & 0.55 & 1.03 & 0.95 & $(0.15)$ & 0.759 & 0.70 & 1.29 \\
\hline & \multicolumn{5}{|c|}{ Business functions } & \multicolumn{5}{|c|}{ Data-driven roles } \\
\hline & $\begin{array}{l}\text { Odds } \\
\text { ratio }\end{array}$ & $\begin{array}{l}\text { Std. } \\
\text { err. }\end{array}$ & $\mathrm{P}>z$ & $\begin{array}{r}{[95 \%} \\
\text { inter }\end{array}$ & Conf. & $\begin{array}{l}\text { Odds } \\
\text { ratio }\end{array}$ & $\begin{array}{l}\text { Std. } \\
\text { err. }\end{array}$ & $\mathrm{P}>z$ & $\begin{array}{r} \\
\text { Co } \\
\text { inter }\end{array}$ & $\begin{array}{l}5 \% \\
\text { rval. } \\
\text { rval] }\end{array}$ \\
\hline Bed size: $50-199$ (reference hospitals $<50$ beds) & 1.04 & $0.14)$ & 0.741 & 0.81 & 1.35 & 1.30 & $(0.18)$ & 0.059 & 0.99 & 1.69 \\
\hline Bed size $200-399$ (reference hospitals $<50$ beds) & 1.27 & $(0.21)$ & 0.145 & 0.92 & 1.75 & 1.22 & $(0.21)$ & 0.250 & 0.87 & 1.71 \\
\hline Bed size: $\geq 400$ (reference hospitals $<50$ beds) & 1.14 & $(0.25)$ & 0.551 & 0.74 & 1.75 & 1.57 & $(0.35)$ & 0.042 & 1.02 & 2.44 \\
\hline Ownership: Public (reference nonprofit) & 0.87 & $(0.11)$ & 0.253 & 0.68 & 1.11 & 0.74 & $(0.10)$ & 0.020 & 0.58 & 0.95 \\
\hline Ownership: Investor (reference nonprofit) & 0.71 & $(0.13)$ & 0.063 & 0.49 & 1.02 & 0.46 & $(0.09)$ & 0.000 & 0.31 & 0.68 \\
\hline System member & 1.13 & $(0.12)$ & 0.264 & 0.91 & 1.39 & 1.30 & $(0.14)$ & 0.018 & 1.05 & 1.61 \\
\hline Teaching & 0.92 & $(0.20)$ & 0.705 & 0.61 & 1.40 & 0.98 & $(0.22)$ & 0.918 & 0.63 & 1.51 \\
\hline General medical center & 1.19 & $(0.19)$ & 0.269 & 0.88 & 1.61 & 1.05 & $(0.17)$ & 0.782 & 0.76 & 1.43 \\
\hline Urban & 1.15 & $(0.15)$ & 0.275 & 0.89 & 1.49 & 1.11 & $(0.15)$ & 0.439 & 0.85 & 1.45 \\
\hline Uninsured rate & 1.02 & $(0.01)$ & 0.234 & 0.99 & 1.05 & 0.97 & $(0.01)$ & 0.036 & 0.94 & 1.00 \\
\hline Poverty rate & 1.02 & $(0.02)$ & 0.209 & 0.99 & 1.05 & 1.01 & $(0.02)$ & 0.507 & 0.98 & 1.04 \\
\hline Population poor, fair health & 0.98 & $(0.02)$ & 0.334 & 0.93 & 1.02 & 0.97 & $(0.03)$ & 0.253 & 0.92 & 1.02 \\
\hline Region: Northeast (reference South) & 0.92 & $(0.16)$ & 0.622 & 0.64 & 1.30 & 0.54 & $(0.10)$ & 0.001 & 0.38 & 0.76 \\
\hline Region: Midwest (reference South) & 1.06 & $(0.16)$ & 0.687 & 0.80 & 1.41 & 0.77 & $(0.12)$ & 0.092 & 0.57 & 1.04 \\
\hline \multirow[t]{3}{*}{ Region: West (reference South) } & 1.06 & $(0.16)$ & 0.678 & 0.79 & 1.44 & 0.95 & $(0.15)$ & 0.773 & 0.70 & 1.31 \\
\hline & \multicolumn{5}{|c|}{ Behavioral health } & \multicolumn{5}{|c|}{ Selected other } \\
\hline & $\begin{array}{l}\text { Odds } \\
\text { ratio }\end{array}$ & $\begin{array}{l}\text { Std. } \\
\text { err. }\end{array}$ & $\mathrm{P}>z$ & \multicolumn{2}{|c|}{$\begin{array}{c}{[95 \%} \\
\text { Conf. } \\
\text { interval] }\end{array}$} & $\begin{array}{c}\text { Odds } \\
\text { ratio }\end{array}$ & $\begin{array}{l}\text { Std. } \\
\text { err. }\end{array}$ & $\mathrm{P}>z$ & $\begin{array}{r}{[9 .} \\
\text { Co } \\
\text { inter }\end{array}$ & $\begin{array}{l}5 \% \\
n f . \\
\text { val] }\end{array}$ \\
\hline Bed $s$ & 1.61 & $(0.25)$ & 0.001 & 1.21 & 2.15 & 0.99 & $(0.36)$ & 0.972 & 0.48 & 2.00 \\
\hline Bed size $200-399$ (reference hospitals $<50$ beds) & 1.66 & $(0.30)$ & 0.005 & 1.17 & 2.36 & 1.44 & $(0.56)$ & 0.353 & 0.67 & 3.10 \\
\hline Bed size: $\geq 400$ (reference hospitals $<50$ beds) & 2.09 & $(0.47)$ & 0.001 & 1.34 & 3.26 & 1.51 & $(0.71)$ & 0.379 & 0.60 & 3.81 \\
\hline Ownership: Public (reference nonprofit) & 1.32 & $(0.17)$ & 0.036 & 1.02 & 1.71 & 0.55 & $(0.18)$ & 0.066 & 0.29 & 1.04 \\
\hline Ownership: Investor (reference nonprofit) & 0.91 & $(0.19)$ & 0.633 & 0.60 & 1.36 & 0.32 & $(0.17)$ & 0.029 & 0.12 & 0.89 \\
\hline System member & 1.33 & $(0.15)$ & 0.011 & 1.07 & 1.67 & 1.98 & $(0.53)$ & 0.011 & 1.17 & 3.33 \\
\hline Teaching & 1.00 & $(0.21)$ & 0.992 & 0.65 & 1.52 & 1.19 & $(0.47)$ & 0.665 & 0.55 & 2.57 \\
\hline General medical center & 0.76 & $(0.13)$ & 0.092 & 0.55 & 1.05 & 0.83 & $(0.29)$ & 0.591 & 0.42 & 1.65 \\
\hline Urban & 0.94 & $(0.13)$ & 0.674 & 0.71 & 1.24 & 2.63 & $(0.97)$ & 0.008 & 1.28 & 5.41 \\
\hline Uninsured rate & 0.98 & $(0.02)$ & 0.323 & 0.96 & 1.02 & 0.96 & $(0.04)$ & 0.270 & 0.89 & 1.03 \\
\hline Poverty rate & 1.04 & $(0.02)$ & 0.029 & 1.00 & 1.07 & 0.99 & $(0.04)$ & 0.808 & 0.92 & 1.07 \\
\hline Population poor, fair $h$ & 0.95 & $(0.03)$ & 0.069 & 0.90 & 1.00 & 1.11 & $(0.06)$ & 0.079 & 0.99 & 1.24 \\
\hline Region: Northeast (reference South) & 1.39 & $(0.26)$ & 0.078 & 0.96 & 2.00 & 0.93 & $(0.39)$ & 0.859 & 0.41 & 2.10 \\
\hline Region: Midwest (reference South) & 1.14 & $(0.218)$ & 0.395 & 0.84 & 1.56 & 1.88 & $(0.63)$ & 0.061 & 0.97 & 3.63 \\
\hline Region: West (reference South) & 1.07 & $(0.18)$ & 0.660 & 0.77 & 1.51 & 2.39 & $(0.83)$ & 0.012 & 1.21 & 4.70 \\
\hline
\end{tabular}

Post hoc analysis of psychiatric hospitals (instead of general medical) as an independent variable for behavioral health was strongly associated with behavioral health roles; odds ratio 4.66, P.000.

Source: American Hospital Association Population Health Survey 2015. ${ }^{34}$ 
Table 4. Multinomial Logistic Regression Hospital Ranking of Future Population Health Roles by Hospital and Community Characteristics (Reference Group Clinical Roles N=1129 Hospitals)

\begin{tabular}{|c|c|c|c|c|c|c|c|c|c|c|}
\hline \multirow[b]{3}{*}{ Bed size: $50-199$} & \multicolumn{5}{|c|}{ Social supports and services } & \multicolumn{5}{|c|}{ Behavioral health } \\
\hline & \multirow{2}{*}{$\begin{array}{l}R R R \\
0.67\end{array}$} & \multirow{2}{*}{$\begin{array}{c}\text { Std. err } \\
(0.15)\end{array}$} & \multirow{2}{*}{$\begin{array}{c}\mathrm{P} \\
0.075\end{array}$} & \multicolumn{2}{|c|}{$\begin{array}{c}\text { Confidence } \\
\text { interval }\end{array}$} & \multirow{2}{*}{$\begin{array}{r}R R R \\
1.07\end{array}$} & \multirow{2}{*}{$\begin{array}{c}\text { Std. err } \\
(0.27)\end{array}$} & \multirow{2}{*}{$\frac{P}{0.784}$} & \multicolumn{2}{|c|}{$\begin{array}{c}\text { Confidence } \\
\text { interval }\end{array}$} \\
\hline & & & & 0.43 & 1.04 & & & & 0.65 & 1.76 \\
\hline Bed size $200-399$ & 0.40 & $(0.12)$ & 0.002 & 0.22 & 0.70 & 0.64 & $(0.22)$ & 0.193 & 0.33 & 1.25 \\
\hline Bed size: $\geq 400$ & 0.33 & $(0.13)$ & 0.005 & 0.16 & 0.71 & 0.75 & $(0.32)$ & 0.508 & 0.32 & 1.75 \\
\hline Ownership: Public (reference nonprofit) & 0.75 & $(0.16)$ & 0.169 & 0.49 & 1.13 & 1.34 & $(0.32)$ & 0.212 & 0.85 & 2.13 \\
\hline Ownership: Investor (reference nonprofit) & 0.48 & $(0.18)$ & 0.052 & 0.23 & 1.01 & 1.51 & $(0.51)$ & 0.227 & 0.77 & 2.94 \\
\hline System member & 0.73 & $(0.14)$ & 0.093 & 0.51 & 1.05 & 0.76 & $(0.16)$ & 0.196 & 0.50 & 1.15 \\
\hline Teaching & 1.69 & $(0.65)$ & 0.174 & 0.79 & 3.60 & 1.34 & $(0.58)$ & 0.494 & 0.58 & 3.14 \\
\hline General medical center & 0.95 & $(0.28)$ & 0.873 & 0.53 & 1.70 & 0.30 & $(0.08)$ & 0.000 & 0.17 & 0.50 \\
\hline Urban & 0.85 & $(0.19)$ & 0.446 & 0.55 & 1.30 & 0.65 & $(0.16)$ & 0.088 & 0.40 & 1.07 \\
\hline Uninsured rate & 1.02 & $(0.03)$ & 0.452 & 0.97 & 1.07 & 1.02 & $(0.03)$ & 0.536 & 0.96 & 1.08 \\
\hline Poverty rate & 1.08 & $(0.03)$ & 0.009 & 1.02 & 1.14 & 1.06 & $(0.03)$ & 0.094 & 0.99 & 1.12 \\
\hline Population poor, fair health & 0.89 & $(0.04)$ & 0.009 & 0.82 & 0.97 & 0.92 & $(0.05)$ & 0.082 & 0.83 & 1.01 \\
\hline Region: Northeast (reference South) & 1.11 & $(0.35)$ & 0.728 & 0.61 & 2.05 & 1.84 & $(0.64)$ & 0.079 & 0.93 & 3.63 \\
\hline Region: Midwest (reference South) & 0.73 & $(0.19)$ & 0.230 & 0.44 & 1.22 & 0.99 & $(0.30)$ & 0.986 & 0.55 & 1.80 \\
\hline \multirow[t]{3}{*}{ Region: West (reference South) } & 1.31 & $(0.36)$ & 0.330 & 0.76 & 2.25 & 1.74 & $(0.55)$ & 0.079 & 0.94 & 3.22 \\
\hline & \multicolumn{5}{|c|}{ Data driven } & \multicolumn{5}{|c|}{ Business functions } \\
\hline & $R R R$ & Std. err & $\mathrm{P}$ & \multicolumn{2}{|c|}{$\begin{array}{c}\text { Confidence } \\
\text { interval }\end{array}$} & $R R R$ & Std. err & $\mathrm{P}$ & $\begin{array}{r}\text { Con } \\
\text { int }\end{array}$ & $\begin{array}{l}\text { ence } \\
\text { al }\end{array}$ \\
\hline Bed size: $50-199$ & 0.93 & $(0.24)$ & 0.790 & 0.56 & 1.55 & 0.70 & $(0.19)$ & 0.186 & 0.41 & 1.19 \\
\hline Bed size 200-399 & 0.94 & $(0.29)$ & 0.841 & 0.51 & 1.72 & 0.72 & $(0.23)$ & 0.292 & 0.38 & 1.33 \\
\hline Bed size: $\geq 400$ & 0.75 & $(0.30)$ & 0.460 & 0.34 & 1.63 & 0.67 & $(0.27)$ & 0.321 & 0.31 & 1.47 \\
\hline Ownership: Public (reference nonprofit) & 0.70 & $(0.17)$ & 0.131 & 0.44 & 1.11 & 0.66 & $(0.16)$ & 0.094 & 0.40 & 1.07 \\
\hline Ownership: Investor (reference nonprofit) & 0.77 & $(0.29)$ & 0.478 & 0.37 & 1.60 & 0.56 & $(0.22)$ & 0.135 & 0.26 & 1.20 \\
\hline System member & 0.74 & $(0.15)$ & 0.134 & 0.50 & 1.10 & 0.84 & $(0.18)$ & 0.417 & 0.56 & 1.27 \\
\hline Teaching & 2.12 & $(0.77)$ & 0.039 & 1.04 & 4.34 & 1.16 & $(0.45)$ & 0.706 & 0.54 & 2.49 \\
\hline General medical center & 0.84 & $(0.26)$ & 0.565 & 0.46 & 1.53 & 0.69 & $(0.21)$ & 0.212 & 0.38 & 1.24 \\
\hline Urban & 0.87 & $(0.21)$ & 0.571 & 0.54 & 1.41 & 1.34 & $(0.36)$ & 0.267 & 0.80 & 2.25 \\
\hline Uninsured rate & 1.01 & $(0.03)$ & 0.811 & 0.95 & 1.07 & 1.10 & $(0.03)$ & 0.000 & 1.04 & 1.16 \\
\hline Poverty rate & 1.05 & $(0.03)$ & 0.105 & 0.99 & 1.12 & 1.02 & $(0.03)$ & 0.451 & 0.96 & 1.09 \\
\hline Population poor, fair health & 0.89 & $(0.04)$ & 0.013 & 0.81 & 0.98 & 0.91 & $(0.05)$ & 0.058 & 0.83 & 1.00 \\
\hline Region: Northeast (reference South) & 0.60 & $(0.20)$ & 0.133 & 0.31 & 1.17 & 1.67 & $(0.56)$ & 0.123 & 0.87 & 3.22 \\
\hline Region: Midwest (reference South) & 0.69 & $(0.19)$ & 0.183 & 0.41 & 1.19 & 1.22 & $(0.35)$ & 0.493 & 0.69 & 2.16 \\
\hline Region: West (reference South) & 1.10 & $(0.33)$ & 0.753 & 0.61 & 1.97 & 1.30 & $(0.40)$ & 0.387 & 0.71 & 2.38 \\
\hline & & & & Selecte & her & & & & & \\
\hline & $R R$ & Std & l. err & $\mathrm{P}$ & $\mathrm{Con}$ & ence & terval & & & \\
\hline Bed size: $50-199$ & 2.6 & & $.94)$ & 0.394 & 0.29 & & 23.69 & & & \\
\hline Bed size 200-399 & 5.6 & & $.25)$ & 0.122 & 0.63 & & 49.84 & & & \\
\hline Bed size: $\geq 400$ & 2.9 & & $.53)$ & 0.378 & 0.27 & & 31.37 & & & \\
\hline Ownership: Public (reference nonprofit) & 0.7 & & $.43)$ & 0.653 & 0.27 & & 2.29 & & & \\
\hline Ownership: Investor (reference nonprofit) & 0.0 & & $.00)$ & 0.973 & 0.00 & & & & & \\
\hline System member & 2.0 & & $.10)$ & 0.158 & 0.75 & & 5.84 & & & \\
\hline Teaching & 1.1 & & $.81)$ & 0.804 & 0.31 & & 4.53 & & & \\
\hline General medical center & 1.1 & & .89) & 0.872 & 0.24 & & 5.30 & & & \\
\hline Urban & 6.7 & & $.31)$ & 0.079 & 0.80 & & 56.51 & & & \\
\hline Uninsured rate & 0.9 & & $.07)$ & 0.501 & 0.83 & & 1.10 & & & \\
\hline Poverty rate & 1.0 & & $.07)$ & 0.954 & 0.87 & & 1.14 & & & \\
\hline Population poor, fair health & 1.1 & & $.12)$ & 0.216 & 0.93 & & 1.40 & & & \\
\hline Region: Northeast (reference South) & 0.8 & & $.63)$ & 0.860 & 0.22 & & 3.57 & & & \\
\hline Region: Midwest (reference South) & 1.3 & & .79) & 0.653 & 0.40 & & 4.30 & & & \\
\hline Region: West (reference South) & 4.2 & & $.38)$ & 0.010 & 1.40 & & 12.75 & & & \\
\hline
\end{tabular}

Source: American Hospital Association Population Health Survey 2015. ${ }^{34}$

RRR, relative risk ratio. 
choice in similar numbers to data-driven and business functions, it was only included in the rankings overall by $41 \%$ of hospitals. Other research has shown that hospitals are hesitant to address behavioral health as part of their population health efforts and show a tendency to cede behavioral health issues to other types of facilities, ${ }^{41,42}$ which may be the case here as well.

Present study findings also indicate that the structure of hospitals may influence strategic planning decisions in regard to population health. Responses from larger hospitals convey that they, in particular, view their roles as primarily clinical. For-profit hospitals are the least likely to prioritize social supports and services and also are less likely to value investing in data-driven roles. These findings may speak to how for-profit hospitals view their clinical mission as compared to their nonprofit counterparts. Given that much of the focus on population health has been connected with community benefit requirements that are only leveraged on nonprofit hospitals, for-profit hospitals may see social support services as beyond their scope of work.

Perhaps most notable in this analysis of the top-ranked professions are the findings regarding self-rated health among individuals residing proximate to the hospital. It can be seen that counties with a higher proportion of individuals stating that their health is either fair or poor were less likely to have hospitals that listed social services or data-driven roles as their top priority, in comparison to clinical roles. A large body of literature suggests that self-rated health is a strong and independent predictor of mortality as well as a number of other chronic and behavioral health conditions. ${ }^{43,44}$ Therefore, study findings suggest that hospitals in communities with greater health needs may be less likely to adopt preventive practices or engage upstream social determinants of health. Put simply, clinical roles, which are already the most commonly listed top choice, are prioritized at even greater rates in communities with poorer health outcomes. At the same time, hospitals located in communities that are economically vulnerable are more likely to prioritize roles that transcend their traditional clinical expertise. County-level poverty rate is associated with prioritization of social services, which may be a recognition of the need to engage social, as opposed to medical, services in those communities. Similarly, the county uninsurance rate is associated with a prioritization of business functions, which may suggest that hospitals are recognizing the need to expand their services in areas where patients face insurance-related barriers to accessing medical care.

There may be a number of reasons why so many hospitals consider clinical roles as their best strategy to address population health, even as their communities experience significant social needs that impact health outcomes. It is important to remember that hospitals have traditionally operated as clinical care facilities and do not typically have expertise in some domains related to population health, including social support services and data collection. In addition, the current mechanisms by which hospitals are reimbursed continue to emphasize clinical service provision. The means of supporting many of the other roles listed may be less clear. As ways are considered to encourage hospitals to fully collaborate in population health efforts with local stakeholders, it may be of value to explore new payment reforms that specifically emphasize population health outcomes in addition to quality and cost-effectiveness of care.
Another explanation for hospitals' support of clinical roles could pertain to the ongoing shortage of health professionals. ${ }^{45}$ With increasingly challenging expectations from regulatory agencies, transitioning to quality-based payment reforms, and growing consumer demands, providers' time and energy are being stretched. At the same time, providers are becoming more acutely aware of the role of social factors on individual and population health and the importance of holistic health care. ${ }^{46}$ Although there are a growing number of examples of how social factors are being addressed in interventions staged by health care organizations, integration of this information into clinical visits is still relatively uncommon. A recent study found that only $23 \%$ of clinicians ask patients about social needs, $22 \%$ review social needs in medical records, and $35 \%$ assess social needs in clinical decision making. ${ }^{32}$ The main barriers intensifying limited focus on social needs are a lack of time and resources. ${ }^{32}$ It is possible that hospitals are more likely to prioritize expanding their physician workforce because increased clinical personnel could afford more time with patients, which could improve trust, communication, and inclusion of social support metrics in clinical decision making. Given existing evidence regarding the relative impact of health care vs. social service interventions to address population health, hospitals may need additional support and partnerships to shift their population health efforts beyond clinical interventions.

\section{Limitations}

Data used in this study provide valuable information regarding how hospitals view their organizations' population health efforts and explore expanding their capacity to address community needs. Nonetheless, it is important to acknowledge that this information is entirely self-reported and was collected as part of an optional, supplemental survey for all AHA hospital members. Hospitals that responded to this survey may share similarities, potentially limiting the ability to generalize to the entire hospital population. Another limitation is that the response options for the survey question this study is based on were listed with little-to-no explanation or definition, requiring some interpretation from the respondent. The research team categorized these responses in an effort to recognize trends and patterns of hospitals' population health priorities, but the team acknowledges that some professional roles could reasonably fall into more than 1 category (eg, a psychiatrist could be considered either clinical or behavioral health). The team also acknowledges limitations in the data that prevented them from assessing the impact of hospitals' finances, profitability, or payor mix, which could influence population health staffing priorities. Furthermore, the team was not able to include information about the full range of factors that might be driving these decisions, such as technological tools or software investments utilized by the hospital, details regarding patient enrollment in accountable care organizations or medical home models, or additional community-level details. Some of these factors may be fruitful grounds for future research into this topic.

\section{Conclusions}

Hospital-led population health initiatives offer promising opportunities to spark fruitful cross-sector partnerships, 
expand the health professional workforce, and engage both patients and communities to prevent and manage chronic illness. Despite this potential, however, this new paradigm poses significant challenges for hospitals that have focused primarily on developing clinical expertise. This study suggests that although hospitals are building their population health efforts, their priorities are most likely to focus on expanding clinical services and personnel as compared to other types of expertise, including social and behavioral health or community health evaluation, which are vital to addressing social determinants of health and redressing persistent population-based health disparities. ${ }^{31}$

Study findings suggest that hospitals will need additional incentives and support to expand their role in addressing social determinants of health and other patient and community health needs. Policy makers should consider new mechanisms that specifically encourage nonclinical contributions to local health outcomes and that utilize partnerships with public health and mental health partners, which experts have identified as critical to boosting population health. ${ }^{9,47}$ These partners are essential to supplementing the clinical expertise that hospitals foster within their organizations. An increased understanding of how hospitals make population health decisions may improve policy makers' abilities to engage with hospitals and encourage collaboration beyond the hospital's own walls.

\section{Author Disclosure Statement}

The authors declare that there are no conflicts of interest.

\section{Funding Information}

No funding was received for this article.

\section{References}

1. Berwick DM, Nolan TW, Whittington J. The triple aim: care, health, and cost. Health Aff (Millwood) 2008;27:759769.

2. Begun JW, Kahn LM, Cunningham BA, Malcolm JK, Potthoff S. A measure of the potential impact of hospital community health activities on population health and equity. J Public Heal Manag Pract 2018;24:417-423.

3. Kindig D, Stoddart G. What is population health? Am J Public Health 2003;93:380-383.

4. Durovich CJ, Roberts PW. Designing a community-based population health model. Popul Health Manag 2018;21: 13-19.

5. DeVore S, Champion RW. Driving population health through accountable care organizations. Health Aff (Millwood) $2011 ; 30: 41-50$.

6. Hacker K, Walker DK. Achieving population health in accountable care organizations. Am J Public Health 2013; 103:1163-1167.

7. James J. Nonprofit hospitals' community benefit requirements. Health Aff 2016:1-5. doi:10.1377/hpb2016.3

8. Rosenbaum S, Byrnes M, Rothenberg S, Gunsalus R. Improving Community Health through Hospital Community Benefit Spending: Charting a Path to Reform. Washington, DC: Milkin Institute School of Public Health, The George Washington University. 2016. http://hsrc.himmelfarb.gwu .edu/cgi/viewcontent.cgi?article=1825\&context=sphhs_policy_ facpubs Accessed April 10, 2019.
9. Sims J, Aboelata MJ. A system of prevention: applying a systems approach to public health. Health Promot Pract 2019;20:476-482.

10. Institute of Medicine. The future of the public's health in the 21 st century. Washington, DC: National Academies Press, 2003.

11. Skinner D, Franz B, Kelleher K. What challenges do nonprofit hospitals face in taking on community health needs assessments? A qualitative study from Appalachian Ohio. J Rural Heal 2018;34:182-192.

12. Skinner D, Franz B, Taylor M, Shaw C, Kelleher KJ. How U.S. children's hospitals define population health: a qualitative, interview-based study. BMC Health Serv Res 2018; 18:494.

13. Laymon B, Shah G, Leep CJ, Elligers JJ, Kumar V. The proof's in the partnerships: are affordable care act and local health department accreditation practices influencing collaborative partnerships in community health assessment and improvement planning? J Public Heal Manag Pract 2015;21:12-17.

14. Kurtzman JH. A community hospital-county health department partnership to reduce preventable readmissions: lessons learned for population health management. J Healthc Manag 2015;60:258-267.

15. Shah GH. Local health departments' role in nonprofit hospitals' community health needs assessment. Am J Public Health 2018;108:595-597.

16. Alfano-Sobsey E, Ledford SL, Decosimo K, Horney JA. Community health needs assessment in Wake County, North Carolina partnership of public health, hospitals, academia, and other stakeholders. N C Med J 2014;75:376-383.

17. Krumwiede KA, Van Gelderen SA, Krumwiede NK. Academic-hospital partnership: conducting a community health needs assessment as a service learning project. Public Health Nurs 2015;32:359-367.

18. Crossley M, Tyler ET, Herbst JL. Law and the public's health: tax-exempt hospitals and community health under the Affordable Care Act: identifying and addressing unmet legal needs as social determinants of health. Public Health Rep 2016;131:195-199.

19. Burke JG, Truong S, Albert S, et al. What can be learned from the types of community benefit programs that hospitals already have in place? J Health Care Poor Underserved 2014;25(suppl 1):165-193.

20. Kirk CM, Johnson-Hakim S, Anglin A, Connelly C. Putting the community back into community health needs assessments: maximizing partnerships via community-based participatory research. Prog Community Health Partnersh 2017;11:167-173.

21. Alderwick H, Gottlieb LM. Meanings and misunderstandings: a social determinants of health lexicon for health care systems. Milbank Q 2019;97:407-419.

22. Kindig D. Population health equity. JAMA 2017;317: 467.

23. Steenkamer BM, Drewes HW, Heijink R, Baan CA, Struijs JN. Defining population health management: a scoping review of the literature. Popul Health Manag 2017; 20:74-85.

24. Hutchison SL, Flanagan JV, Karpov I, et al. Care management intervention to decrease psychiatric and substance use disorder readmissions in Medicaid-enrolled adults. J Behav Health Serv Res 2019;46:533-543.

25. Heaton PC, Frede S, Kordahi A, et al. Improving care transitions through medication therapy management: a 
community partnership to reduce readmissions in multiple health-systems. J Am Pharm Assoc (2003) 2019;59:319_ 328.

26. Jones LK, Greskovic G, Grassi DM, et al. Medication therapy disease management: Geisinger's approach to population health management. Am J Health Syst Pharm 2017;74:1422-1435.

27. Homsted FAE, Magee CE, Nesin N. Population health management in a small health system: impact of controlled substance stewardship in a patient-centered medical home. Am J Health Syst Pharm 2017;74:1468-1475.

28. Mendu ML, Ahmed S, Maron JK, et al. Development of an electronic health record-based chronic kidney disease registry to promote population health management. BMC Nephrol 2019;20:72.

29. Carmichael JM, Meier J, Robinson A, Taylor J, Higgins DT, Patel S. Leveraging electronic medical record data for population health management in the Veterans Health Administration: successes and lessons learned. Am J Health Syst Pharm 2017;74:1447-1459.

30. Rowland T, Nielsen-Farrell J, Church K, Riddell B. Technology-enabled population health management: two communities' use of an electronic care alert system. PM R 2017;9(5S):S75-S84.

31. Kaplan RM, Milstein A. Contributions of health care to longevity: a review of 4 estimation methods. Ann Fam Med 2019;17:267-272.

32. Schickedanz A, Hamity C, Rogers A, Sharp AL, Jackson A. Clinician experiences and attitudes regarding screening for social determinants of health in a large integrated health system. Med Care 2019;57 suppl 6 suppl 2:S197-S201.

33. Noh E, Potthoff S, Begun JW. A taxonomy of hospitals based on partnerships for population health management. Health Care Manage Rev 2018 [Epub ahead of print]; DOI: 10.1097/HMR.0000000000000230.

34. Health Research \& Education Trust. Approaches to Population Health in 2015: A National Survey of Hospitals. 2015. https://www.aha.org/ahahret-guides/2015-08-24-appro aches-population-health-2015-national-survey-hospitals Accessed September 16, 2019.

35. Area Health Resource Files. https://data.hrsa.gov/data/ download. Accessed February 10, 2019.

36. County Health Rankings and Roadmaps. National Data Documentation: 2010-2016. www.countyhealthrankings .org/explore-health-rankings/rankings-data-documentation/ national-data-documentation-2010-2016. Accessed February 2, 2019.

37. Cantor MN, Thorpe L. Integrating data on social determinants of health into electronic health records. Health Aff (Millwood) 2018;37:585-590.
38. Association for Community Affiliated Plans, Center for Health Care Strategies. Addressing Social Determinants of Health via Medicaid Managed Care Contracts and Section 1115 Demonstrations. 2018. www.communityplans.net Accessed September 17, 2019.

39. Rentas KG, Buckley L, Wiest D, Bruno CA. Characteristics and behavioral health needs of patients with patterns of high hospital use: implications for primary care providers. BMC Health Serv Res 2019;19:81.

40. Powell RE, Doty AMB, Rising KL, Karp DN, Baehr A, Carr BG. A content analysis of nonprofit hospital community health needs assessments and community benefit implementation strategies in Philadelphia. J Public Health Manag Pract 2018;24:326-334.

41. Franz B, Skinner D, Kelleher K. Why don't hospitals prioritize substance abuse in their community benefit programming? J Public Health Manag Pract 2019;25: 62-68.

42. Cronin CE, Franz B, Skinner D, Haile ZT. Hospitals and substance use disorder services in the time of the opioid epidemic. Health Serv Res 2019;54:399-406.

43. Latham K, Peek CW. Self-rated health and morbidity onset among late midlife U.S. adults. J Gerontol Ser B Psychol Sci Soc Sci 2013;68:107-116.

44. DeSalvo KB, Bloser N, Reynolds K, He J, Muntner P. Mortality prediction with a single general self-rated health question. J Gen Intern Med 2006;21:267-275.

45. Association of American Medical Colleges. The Complexities of Physician Supply and Demand: Projections from 2016 to 2030. Washington DC: Association of American Medical Colleges, 2018.

46. Gottlieb LM, Wing H, Adler NE. A systematic review of interventions on patients' social and economic needs. Am J Prev Med 2017;53:719-729.

47. Mays GP, Scutchfield FD. Improving Public Health System Performance Through Multiorganizational Partnerships. www.ncbi.nlm.nih.gov/pubmed/20950523 Accessed February 10, 2019.

Address correspondence to: Cory E. Cronin, PhD College of Health Sciences and Professions Ohio University 1 Ohio University Athens, OH 45701 USA

E-mail: croninc@ohio.edu 